\title{
Editorial
}

\section{Dedicated to Professor Piero Cappuccinelli: the man for cooperation with developing countries}

\author{
Salvatore Rubino ${ }^{1,2}$, Pier Luigi Fiori ${ }^{1}$ \\ ${ }^{1}$ Department of Biomedical Sciences, University of Sassari, Sassari, Italy \\ ${ }^{2}$ Editor in Chief, Journal of Infection in Developing Countries
}

Key words: Cooperation; developing countries; microbiology.

J Infect Dev Ctries 2015; 9(6):541-542. doi:10.3855/jidc.7217

(Received and Accepted 01 June 2015)

Copyright $\odot 2015$ Rubino et al. This is an open-access article distributed under the Creative Commons Attribution License, which permits unrestricted use, distribution, and reproduction in any medium, provided the original work is properly cited.

This Special issue of the Journal of Infection in Developing Countries wants to celebrate the activity of Piero Cappuccinelli, Full professor of Clinical Microbiology at the University of Sassari, Sardinia, Italy.

Piero Cappuccinelli is one of the founders and a Senior Editor of JIDC and he is internationally considered the man for cooperation with developing countries.

On the $31^{\text {st }}$ of October 2014, Piero Cappuccinelli (virtually) retired after 44 years of studies and research in the field of basic science, clinical microbiology and parasitology. Piero was born in Dronero (Cuneo, Italy), in 1944. He achieved the Medical Doctor degree in Turin in 1970 working with a pioneer of immunology and microbiology in Italy, Professor Giorgio Cavallo. He immediately became Assistant Professor at the Institute of Microbiology, University of Torino. In 1970-71 he started his experience with developing countries at the College of Medicine, University of Liberia, Monrovia as he was granted an Italian cooperation fellowship for research and training in immunology and tropical microbiology, in collaboration with the Institute of Tropical Medicine, Hamburg, Germany. In 1973 he obtained the postgraduate specialty certificate in Microbiology and Virology at the University of Torino. He moved in 1974 to Sardinia as Associate Professor of Microbiology at Sassari University: this was the beginning of an important scientific carrier; as a first step he established an internationally well-known school of microbiologists. He then became director of the Specialty School in Microbiology and Virology,

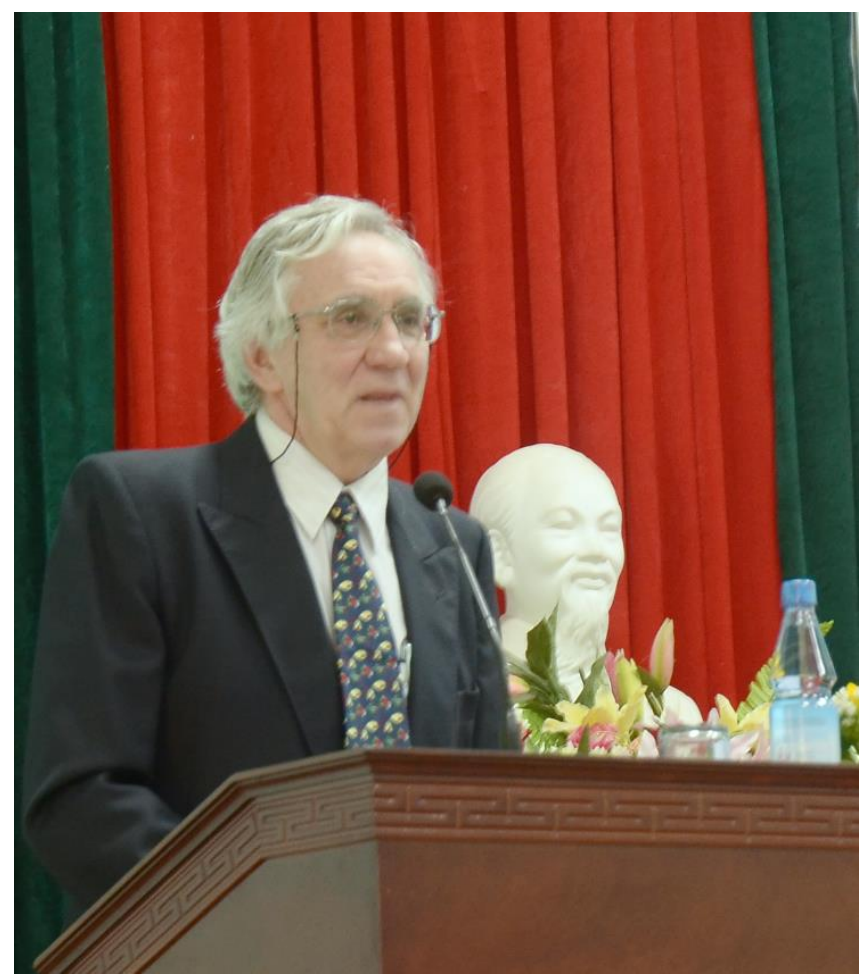

University of Sassari and head of the Clinical Microbiology Laboratories at the University Hospital.

He worked locally on the Island of Sardinia to develop projects involving Scientific innovation and International cooperation. For these reasons he was appointed as President of the Sassari Research Area of the National Research Council (CNR) from 1995 to 2001 and in the same period he became the Chairman of the Committee for international cooperation of the University of Sassari (1998-2010). Between 2004 and 
2010 he served as Vice-president of the Sardinia Governmental Agency (Sardegna Ricerche) for applied research, economic development and implementation of the regional Science and Technology Park known as Polaris. Until recently, he has been one of the fellows and members of the International $\mathrm{PhD}$ School on Biomolecular and Biotechnological Sciences (University of Sassari).

For what concerns the international level he is a member of several Scientific societies, such as: American Society for Microbiology, European Cell Biology Organisation, Italian Society for Microbiology (Member of the Executive Committee in 1992-2001), Italian Society of Protozoology (President from 1991-1995), American Society for Protozoology (Member of the Executive Committee in 1992-96).

$\mathrm{He}$ received several awards during his carreer, only the most prestigious are going to be mentioned: Honorary Visiting Consultant, Mahatma Gandhi Institute of Medical Sciences, Sevagram, India; Honorary Professor, Huè University of Medicine and Pharmacy, Huè City, Vietnam; Medal "For the cause of health", Vietnam Government, Ministry of Health and he is a prestigious member of the Italian Lincean National Academy (Accademia Nazionale dei Lincei).

In 1970 he started to work on the cytoskeleton of the slime mold Dictyostelium discoideum and then on Trichomonas vaginalis and enteric infections, especially on Cholera. He was granted an EMBO long-term fellowship by the Department of Biology, University of Essex, U.K, to carry out research activities in molecular and cell biology of eukaryotic microorganisms and published several relevant papers in international journals.

In 1986 he started his collaboration with the Italian Ministry of Foreign Affairs becoming a long-term consultant for the Italian Cooperation in Mozambique and was appointed as the head of programmes on epidemiological surveillance, infectious diseases control and training of health personnel. After this two-year experience in Mozambique till today, he performed several missions as short-term consultant of the Italian Cooperation as well as for European and international Agencies in Albania, Angola, Chad, China, D.R. Congo, Ecuador, Egypt, India, Iraq, Laos, Lesotho, Libya, Morocco, Mozambique, Myanmar, Syria, Tanzania, Thailand, Vietnam, Zambia, and Zimbabwe for programmes based on university cooperation, scientific infrastructure organization and technology transfer, training of health personnel, epidemiological surveillance and control of infectious diseases. He has been Scientific director for long-term projects of the Italian cooperation in Mozambique from 1986 to 1988 . Then he organized a laboratorybased epidemiological surveillance network and training for laboratory personnel in Angola from 1997to 2002; he set up the National Public Health Laboratories and organized an epidemiological surveillance network in Mozambique from 2003 till now, to give Institutional support to the College of Medicine and the Biotechnology Centre, E. Mondlane University, Maputo.

He carried out short missions in years 2003-2007 in Zimbabwe at the University of Zimbabwe where he worked to set up a centre for training, reference and research on enteric and urogenital infections. Recently he served in Irak from 2010 to 2014 in DhiQar Province and Kurdistan Autonomous Region.

$\mathrm{He}$ implemented different training and capacity building activities for improving clinical attainment of the Provincial Hospitals in Vietnam, between 20072012 at Huè University of Medicine and Pharmacy, where he founded the Carlo Urbani Centre on training, research and reference for control of respiratory infections in central Vietnam. Since 2011 he also worked at Huè University of Medicine and Pharmacy setting up an International Institute for Biomedical Research and Biotechnology.

During his Scientific career he was author of more than 200 works published on Italian and international journals and books as well as author and editor in 4 scientific books. His main research areas being: mechanisms of virulence and antibiotic resistance of microbial pathogens; molecular methods for diagnosis of infectious diseases; molecular epidemiology and control of infectious diseases in tropical countries.

JIDC is proud to dedicate this issue to a master of life, science and a researcher with high sensibility for health issues in developing countries. A mentor for hundreds of students, medical doctors and laboratory specialists mostly coming from developing countries and particularly from Vietnam in the recent period. Professor Cappuccinelli will be honoured by an International Conference that will be held in Sassari on the $8^{\text {th }}$ of June with the title "From Basic Research to International Cooperation" with the key lecture of the Nobel Laureate Martin Chalfie, Department of Biological Sciences, Columbia University, New York, USA with a speech on "Green Fluorescent Protein: Lighting Up Life".

We thank all authors, editors, reviewers and other colleagues who collaborated with JIDC on this initiative. 